\title{
Southwestern Oncology Group pretreatment risk criteria as predictive or prognostic factors in acute myeloid leukemia
}

\author{
ANA ESPIRITO SANTO ${ }^{1,2}$, SERGIO CHACIM ${ }^{1}$, ISABEL FERREIRA ${ }^{1}$, LUIS LEITE ${ }^{1}$, CLAUDIA MOREIRA ${ }^{1}$, \\ DULCINEIA PEREIRA ${ }^{1}$, MARGARIDA DANTAS $^{1}$, MARTA NUNES $^{1}$, LUISA VITERBO $^{1}$, ILIDIA MOREIRA $^{1}$, \\ ANGELO MARTINS $^{1}$, ISABEL OLIVEIRA ${ }^{1}$, NELSON DOMINGUES ${ }^{1}$, JOSE MARIZ $^{1}$ and RUI MEDEIROS ${ }^{3-7}$ \\ ${ }^{1}$ Department of Onco-Hematology, Portuguese Institute of Oncology, 4200-072 Porto; ${ }^{2}$ Faculty of Medicine, \\ University of Porto, 4000-286 Porto; ${ }^{3}$ Molecular Oncology Group-CI, Portuguese Institute of Oncology, 4200-072 Porto; \\ ${ }^{4}$ Abel Salazar Institute of Biomedical Sciences, University of Porto, 4000-286 Porto; ${ }^{5}$ Oncology Department, \\ Portuguese Institute of Oncology, 4200-072 Porto; ${ }^{6}$ Biomedical Research Center, Faculty of Health Sciences, \\ Fernando Pessoa University, 4000-286 Porto; ${ }^{7}$ Research Department, Portuguese
}

League Against Cancer, 4200-072 Porto, Portugal

Received April 16, 2016; Accepted July 25, 2017

DOI: $10.3892 / \mathrm{mco} .2017 .1134$

\begin{abstract}
Acute myeloid leukemia (AML) is a clonal hematological malignant condition and the implications of pretreatment risk criteria as predictive or prognostic factors are constantly under evaluation. With this study, the authors' intent was to characterize AML patients and to evaluate the clinical outcome associated with Southwestern Oncology Group (SWOG) coding pretreatment risk criteria/cytogenetic score. Between 2002 and 2010, 225 patients were diagnosed with AML at the Portuguese Institute of Oncology (Porto, Portugal). From this patient group, 128 patients aged $<65$ years were selected. The patients were treated using a combination of cytarabine and anthracycline, with the addition of cyclosporine when bone marrow dysplasia was observed. A median survival of 24 months was observed in this group. The patients were divided in subgroups according to the SWOG pretreatment risk criteria. We observed a statistically significant association of non-favorable SWOG coding with female gender $[\mathrm{P}=0.025$; risk ratio $(\mathrm{RR})=3.632,95 \%$ confidence interval $(\mathrm{CI}): 1.113-11.852]$, indication for allogeneic bone marrow transplantation $(\mathrm{P}=0.023$, $\mathrm{RR}=1.317,95 \% \mathrm{CI}: 1.184-1.465)$, complete response achievement $(\mathrm{P}=0.013, \mathrm{RR}=1.385,95 \% \mathrm{CI}: 11.232-1.556)$ and relapse $(\mathrm{P}=0.048, \mathrm{RR}=3.181$, 95\% CI: 10.966-10.478). Furthermore, SWOG pretreatment risk criteria also significantly affected global overall survival $(\mathrm{OS} ; \mathrm{P}=0.003)$ and $\mathrm{OS}$ at 5 years $(\mathrm{P}=0.001)$. A multivariate $\mathrm{Cox}$ regression analysis supported
\end{abstract}

Correspondence to: $\mathrm{Dr}$ Ana Espirito Santo, Department of Onco-Hematology, Portuguese Institute of Oncology, Piso 6 Medicina, Dr António Bernardino de Almeida Street, 4200-072 Porto, Portugal

E-mail: ana.esanto@ipoporto.min-saude.pt

Key words: acute myeloid leukemia, treatment, outcome, cytogenetics, prognosis response to induction therapy (3-year OS: $\mathrm{P}=0.011, \mathrm{RR}=0.385$, 95\% CI: 10.184-0.806; 5-year OS: $\mathrm{P}=0.012$, RR=0.388, 95\% CI: 10.597-1.994), consolidation (3-year OS: $\mathrm{P}=0.005$, $\mathrm{RR}=0.328,95 \%$ CI: $0.150-0.720 ; 5$-year OS: $\mathrm{P}=0.002, \mathrm{RR}=0.308$, 95\% CI: 0.144-0.657) and the diagnosis of therapy-related AML (3-year OS: $\mathrm{P}=0.016, \mathrm{RR}=2.756,95 \%$ CI: 0.486-1.281; 5-year OS: $\mathrm{P}=0.031, \mathrm{RR}=2.369,95 \% \mathrm{CI}: 1.081-5.189)$ as prognostic factors, but this was not confirmed for SWOG pretreatment risk criteria. Therefore, we concluded that the reproducibility of the application of the SWOG pretreatment risk criteria may not be available as a prognostic factor in every acute leukemia population. However, its application as a predictive factor of response has been confirmed in our population.

\section{Introduction}

Acute leukemias are clonal malignant disorders arising from the primitive pluripotent hematopoietic cell, characterized by impaired proliferation of leukemic progenitors $(1,2)$. They are characterized by recurring chromosomal aberrations and gene mutations, with contribution of epigenetic modifications (3), which are crucial in differentiation, proliferation and survival pathways.

According to the latest GLOBOCAN data published in 2012, 351,965 individuals worldwide were diagnosed with leukemia (chronic and acute, as well as lymphoid and myeloid) and 265,491 succumbed to this disease. A marginal male predominance was also reported by the World Health Organization (WHO), with a male:female ratio of $\sim 1.4$ (http:// globocan.iarc.fr/Default.aspx).

The diagnosis is based on bone marrow analysis: A smear morphology with a blast count $>20 \%$ or the presence of recurring cytogenetic abnormalities $[\mathrm{t}(8,21)$, inv16, $\mathrm{t}(16,16)$, or $\mathrm{t}(15,17)]$ confirms the diagnosis $(4)$.

The classification of acute leukemia, previously based only on morphological and cytochemistry findings, from 2002 onwards it includes phenotypic aspects, as well as cytogenetic 
and molecular characteristics, which are of well-known prognostic value (4).

Over the last 30 years, conventional treatment has been based on the combination of anthracyclines with cytarabine (5). The outcome depends on multiple characteristics, including karyotype (6-9), response to the induction regimen (10), age and comorbid conditions (11). AML originating de novo vs. therapy-related, was also associated with outcome. As cytogenetics is considered the single most important prognostic marker, predicting remission, relapse and overall survival (OS), several cooperative group trials, including the United Kingdom Medical Research Council, Southwest Oncology Group (SWOG), Eastern Cooperative Oncology Group and Cancer and Leukemia Group B, designed risk scores based on large cohorts of patients $(6,8,9,12)$, dividing patients in four groups, namely favorable, intermediate, unfavorable and unknown, based on the cytogenetic findings.

However, despite these efforts, the cure rates remain disappointing, with complete response rates at first induction of $60-80 \%$ (age $<60$ years), but with cure rates of $30-40 \%$ (13).

The aim of the present study was to investigate the Portuguese AML population and assess the effect of cytogenetics.

\section{Patients and methods}

Study design. A retrospective observational study was conducted, including AML patients aged $<65$ years, diagnosed and treated at the Portuguese Institute of Oncology (Porto, Portugal), between January, 2002 and December, 2010.

Patients. Between 2002 and 2010, a total of 225 patients were diagnosed with AML in our department. Following exclusion of patients aged $>65$ years and cases with acute promyelocytic leukemia, 128 patients were selected for inclusion in this cohort.

Data regarding gender, age, date of diagnosis, WHO classification, cytogenetic abnormalities, SWOG pretreatment risk score (6), first- and further-line treatment, response, consolidation, relapse, date of relapse, bone marrow transplantation (allogeneic or autologous), date of last hospital visit or date and cause of death, were obtained from the medical records of previously selected patients and retrospectively reviewed.

Diagnosis was based on standard criteria $(4,14,15)$. All cases initially classified according to the French American British classification (14) were reviewed and reclassified according to WHO (4). A blast count $>20 \%$ confirmed the diagnosis of AML.

Specimens were collected for morphological, immunophenotypic and genetic analyses (cytogenetic and molecular biology).

The patients were treated with the classic idarubicin and cytarabine combination $(16,17)$ or with daunorubicin, cytarabine and cyclosporine $(18,19)$ if bone marrow dysplasia was present.

The response criteria used (complete remission, failure or relapse) were defined by international working groups $(4,15,20,21)$.

This investigation was performed in accordance with the principles of the Declaration of Helsinki and was approved by the local Ethics Committee.
Cytogenetics. Standard G-banding was performed on patient bone marrow samples using standard techniques; the cytogenetic results were presented according to the International System for Human Cytogenetic Nomenclature (22). The patients were then analysed according to the cytogenetic risk subgroups defined by the SWOG (6).

Statistical analysis. Analysis of data was performed using the SPSS statistical software for Windows, version 17.0 (SPSS Inc., Chicago, IL, USA). Differences in proportions were evaluated by the Chi-square test. The probabilities of survival were calculated, and the means and life tables were computed using the product limit estimate of the Kaplan-Meier method and analysed using the Breslow (generalized Wilcoxon) test, a statistical test for equality of survival distributions. $\mathrm{P}<0.05$ was considered to indicate statistically significant differences. Hazard ratio was also accessed using a multivariate Cox regression analysis for 3- and 5-year OS.

Survival duration was defined as the time between diagnosis and death, or the time of the last clinical evaluation.

As defined, prognostic factor is a measurement that is associated with clinical outcome in the absence of therapy or with the application of a standard therapy; predictive factor is a measurement that is associated with response or lack of response to a particular therapy $(23,24)$.

\section{Results}

Patient cohort. Between 2002 and 2010, a total of 225 patients were diagnosed with AML at the Portuguese Institute of Oncology (Porto, Portugal); of those, 128 were aged $<65$ years. Both genders were equally represented with 64 patients. The median age at diagnosis was 54 years (range, 17-65 years). Therapy-related AML constituted $23.1 \%$ of all cases.

Karyotype analysis was performed in all patients; in $2.3 \%$ of the cases $(n=3)$, there were insufficient metaphases for karyotype analysis. A normal karyotype was the most frequent result $(n=54 ; 43.2 \%)$. Core-binding factor anomalies were detected in 17 karyotypes (13.6\%). Anomalies involving chromosomes 5, 7 and 8 were detected in 18 cases (14.4\%); a complex karyotype was observed in $9.6 \%(n=12)$ of the studied cases. Other less frequent alterations were detected in the remaining 24 cases $(19.2 \%)$.

Using the SWOG pretreatment risk criteria system, the intermediate group included the majority of the patients $(55.5 \%$; $n=71)$, whereas 37 patients $(28.9 \%)$ had an unfavorable risk and $17(13,6 \%)$ were included in the favorable group.

There was a statistically significant association between cytogenetic groups and age $(\mathrm{P}=0.031)$, gender $[\mathrm{P}=0.025$; risk ratio $(\mathrm{RR})=3.632 ; 95 \%$ confidence interval $(\mathrm{CI})$ : 1.113-11.852], indication for allogeneic stem cell transplantation $(\mathrm{P}=0.023$; $\mathrm{RR}=1.317$; 95\% CI: 1.184-1.465), complete response achievement $(\mathrm{P}=0.013$; $\mathrm{RR}=1.385 ; 95 \% \mathrm{CI}$ : $1.232-1.556)$ and relapse ( $\mathrm{P}=0.048 ; \mathrm{RR}=3.181 ; 95 \% \mathrm{CI}$ : 0.966-10.478) (Table I). A significant association was also observed with global OS $(\mathrm{P}=0.003)$ and 5-year OS $(\mathrm{P}=0.001)$.

Treatment. Complete remission was achieved in $86.7 \%(n=111)$ of the cases. Relapse occurred in 52 patients $(46.8 \%$ of the responders; $46.5 \%$ of the total population). 
Table I. Characterization of the complete cohort and of the 3 different SWOG pretreatment risk criteria groups.

\begin{tabular}{|c|c|c|c|c|c|c|c|}
\hline \multirow[b]{2}{*}{ Factors } & \multirow[b]{2}{*}{$\begin{array}{c}\text { Total, } \\
128(100.0)\end{array}$} & \multicolumn{4}{|c|}{ SWOG pretreatment risk criteria, n (\%) } & \multirow[b]{2}{*}{ P-value ${ }^{a}$} & \multirow[b]{2}{*}{$\mathrm{RR}^{\mathrm{a}}(95 \% \mathrm{CI})$} \\
\hline & & $\begin{array}{c}\text { Favorable, } \\
17(13.3)\end{array}$ & $\begin{array}{c}\text { Intermediate, } \\
71(55.5)\end{array}$ & $\begin{array}{c}\text { Unfavorable, } \\
37 \text { (28.9) }\end{array}$ & $\begin{array}{l}\text { Unknown, } \\
3(2.3)\end{array}$ & & \\
\hline Median age (years) & 54 & 44 & 52 & 53 & 54 & $0.043^{\mathrm{b}}$ & - \\
\hline Female gender & $64(50.0)$ & $13(76.5)$ & $34(47.9)$ & $17(45.9)$ & $0(0.0)$ & $0.019^{\mathrm{b}}$ & $3.82(1.07-14.92)$ \\
\hline t-AML & $24(23.1)$ & $2(11.8)$ & $11(15.5)$ & $11(29.7)$ & $0(0.0)$ & $0.428^{\mathrm{b}}$ & $1.85(0.36-12.69)$ \\
\hline Treatment ('7+3'). & $87(68.0)$ & $15(88.2)$ & $49(69.0)$ & $22(59.5)$ & $1(33.3)$ & $0.054^{\mathrm{b}}$ & $4.06(0.82-27.17)$ \\
\hline Consolidation & $96(86.5)$ & $17(100.0)$ & $57(86.4)$ & $20(54.1)$ & $2(66.6)$ & $0.248^{\mathrm{b}}$ & $3.23(0.40-69.84)$ \\
\hline Allogeneic stem cell & $26(20.3)$ & $0(0.0)$ & $16(22.5)$ & $10(27.0)$ & $0(0.0)$ & $0.084^{\mathrm{b}}$ & $0.10(0.01-1.49)$ \\
\hline Complete response & $111(86.7)$ & $17(100.0)$ & $66(93.0)$ & $26(70.3)$ & $2(66.6)$ & $0.041^{\mathrm{b}}$ & $6.59(0.86-138.32)$ \\
\hline Relapse & $52(46.5)$ & $4(23.5)$ & $33(50.0)$ & $13(48.1)$ & $2(100.0)$ & $0.040^{\mathrm{b}}$ & $0.30(0.08-1.09)$ \\
\hline OS (months) & 24 & NR & 20 & 14 & 2.4 & $0.006^{\mathrm{c}}$ & - \\
\hline 5-year OS (\%) & 44.5 & 80.9 & 31.3 & 29.4 & 0.0 & $0.003^{\mathrm{c}}$ & - \\
\hline
\end{tabular}

${ }^{a}$ Cytogenetic risk score: non favorable vs. favorable. ${ }^{b} \mathrm{Chi}$-square test. ${ }^{\mathrm{c}}$ Log-rank test. SWOG, Southwestern Oncology Group; RR, risk ratio; CI, confidence interval; t-AML, therapy-related acute myeloid leukemia; OS, overall survival; NR, not reached.

Table II. Multivariable analysis for 5-year overall survival.

\begin{tabular}{lrr}
\hline & & 5-year overall survival \\
\cline { 2 - 3 } Factors & P-value $^{\mathrm{a}}$ & $\mathrm{HR}^{\mathrm{b}}(95 \% \mathrm{CI})$ \\
\hline Female gender & 0.293 & $1.376(0.759-2.494)$ \\
Age & 0.627 & $1.006(0.981-1.031)$ \\
Complete response & 0.019 & $0.421(0.204-0.866)$ \\
Treatment & 0.540 & $1.053(0.893-1.242)$ \\
SWOG pretreatment risk criteria & 0.074 & $1.724(0.949-3.134)$ \\
t-AML & 0.019 & $2.404(1.152-5.017)$ \\
Consolidation therapy & 0.005 & $0.342(0.161-0.727)$ \\
\hline
\end{tabular}

${ }^{\mathrm{a} C h i}$-square test. ${ }^{\mathrm{b}}$ Risk of death within 5 years. HR, hazard ratio; CI, confidence interval; SWOG, Southwestern Oncology Group; t-AML, therapy-related acute myeloid leukemia.

Consolidation followed induction with at least one chemotherapy course (median of 4 courses; range, 1-5) in 96 patients $(86.5 \%)$. All patients from the favorable group followed treatment after induction; $86.4 \%(\mathrm{n}=57)$ and $54.1 \%(\mathrm{n}=20)$ of the patients from the intermediate and unfavorable groups, respectively, received consolidation therapy with hight dose cytarabine.

Allogeneic stem cell bone marrow transplantation was performed in 26 patients. The majority of the transplants $(61.5 \%)$ were performed in the intermediate group $(n=16)$.

Outcome. The median survival including all patients was 24 months. The OS at 3 and 5 years was 48.4 and $44.5 \%$, respectively. Different factors were found to statistically significantly affect $O S$ at 3 and 5 years, such as complete response achievement $(\mathrm{P}<0.001$ for both), SWOG pretreatment risk criteria $(\mathrm{P}=0.001$ for both), presence of therapy-related AML ( $\mathrm{P}<0.001$ for both) and consolidation therapy $(\mathrm{P}<0.001$ for both $)$. Age $(\mathrm{P}=0.024)$ and therapy $(\mathrm{P}=0.01)$ only affected 5-year OS (Fig. 1).
A multivariate Cox regression analysis (Table II) demonstrated that OS at 3 and 5 years was affected by the same factors: Achievement of complete response $(\mathrm{P}=0.011$; $\mathrm{RR}=0.385 ; 95 \% \mathrm{CI}: 0.184-0.806$; and $\mathrm{P}=0.012 ; \mathrm{RR}=0.388$; 95\% CI: 0.597-1.994, respectively), therapy-related AML $(\mathrm{P}=0.016 ; \mathrm{RR}=2.756 ; 95 \% \mathrm{CI}: 0.486-1.281$; and $\mathrm{P}=0.031$; $\mathrm{RR}=2.369$; 95\% CI: 1.081-5.189, respectively) and consolidation therapy $(\mathrm{P}=0.005$; $\mathrm{RR}=0.328 ; 95 \% \mathrm{CI}$ : $0.150-0.720$; and $\mathrm{P}=0.002 ; \mathrm{RR}=0.308 ; 95 \% \mathrm{CI}: 0.144-0.657$, respectively). Other studied variables, such as gender, age ( $<50$ or $>50$ years), therapy and SWOG pretreatment risk criteria did not significantly affect outcome.

\section{Discussion}

To the best of our knowledge, this study is the first to investigate and characterize Portuguese patients diagnosed with AML and their outcome. 
A
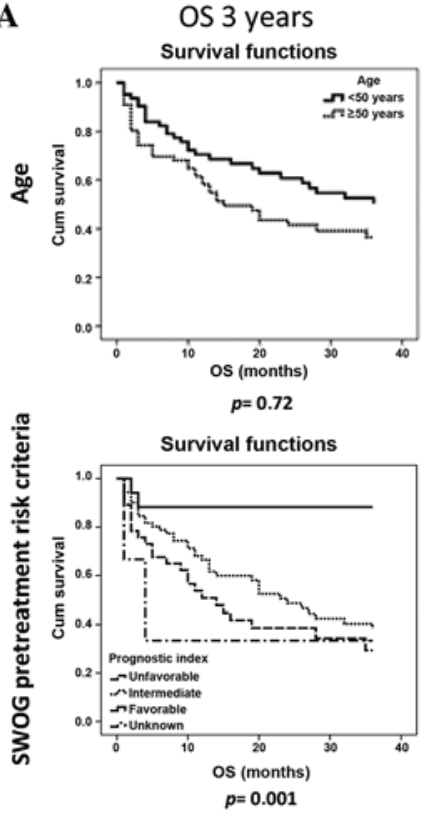

Survival functions

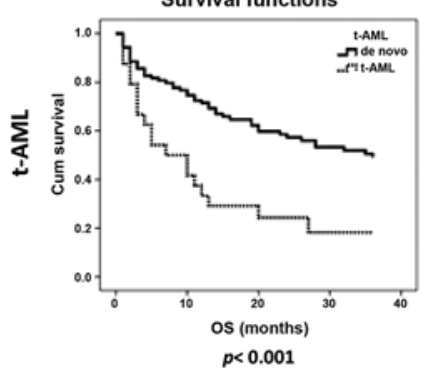

OS 5 years
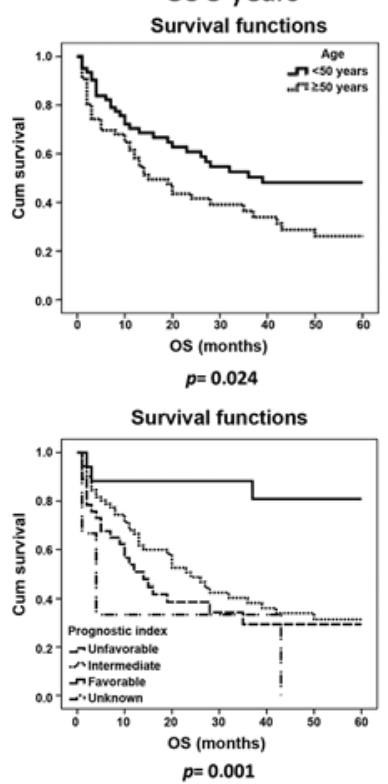

Survival functions

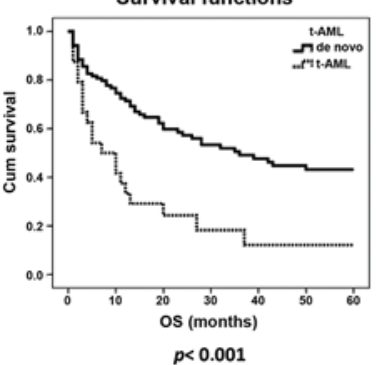

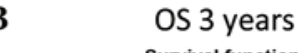

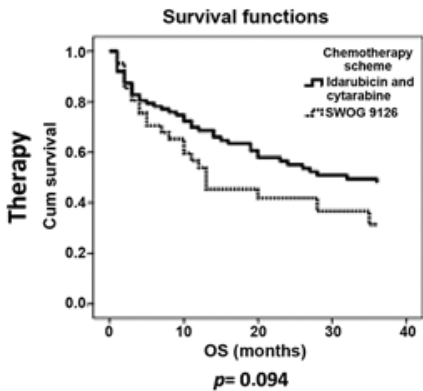

Survival functions

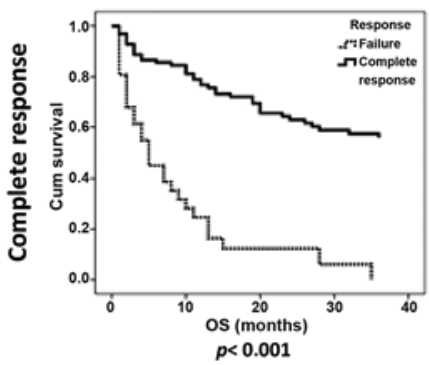

Survival functions

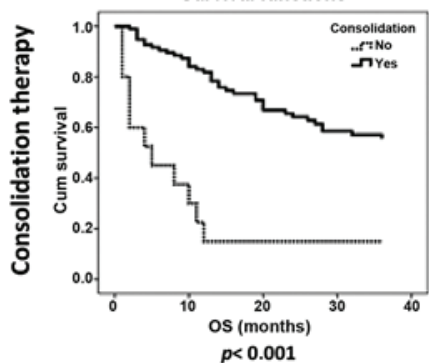

OS 5 years

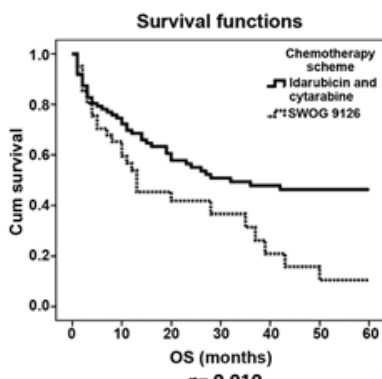

$p=0.010$

Survival functions

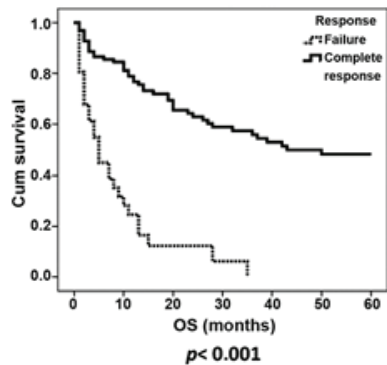

Survival functions

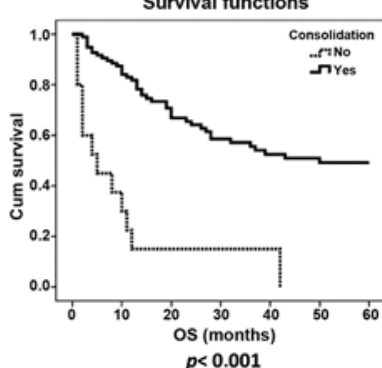

Figure 1. (A) Overall survival (OS) at 3 and 5 years according to age, Southwest Oncology Group (SWOG) pretreatment risk criteria and therapy-related acute myeloid leukemia (t-AML). (B) OS at 3 and 5 years according to complete response achievement, induction therapy and consolidation therapy performed.

In our study, there were more therapy-related AML cases compared with other published series (25). As our hospital is an oncology centre, it admits a high number of cancer patients. When patients develop AML as a secondary malignancy, they are referred to our department.

The most frequent cytogenetic finding was a normal karyotype $(26,27)$. Data on molecular findings were not available for this study. NPM1 and FLT3 gene mutations are now relevant for prognosis assessment (28-32). However, when the patients of this cohort were diagnosed, this molecular analysis was not widely available.

Using the SWOG pretreatment risk criteria, three different groups may be defined, with different survivals. Male gender, failure of complete response achievement, risk of relapse and indication for allogeneic bone marrow transplantation are significantly associated with an unfavorable cytogenetic group. Analysing the effect of age, response to induction, treatment administered, consolidation therapy and t-AML on OS at 3 and 5 years, we observed that all these factors affect outcome. Cytogenetic risk, defined by the SWOG pretreatment risk criteria, also affects OS. However, when analysing this score in association with other factors also related to outcome, such as complete response achievement, cytogenetics does not statistically significantly affect OS. This suggests that cytogenetic groups previously defined and related to disease prognosis $(7,12,33,34)$ may be factors predictive of response, being statistically relevant for complete response to induction therapy, but not prognostic factors, having no statistical significance in OS when associated with other entities.

Predictive and prognostic factor are definitions frequently confused and overlapping. As defined in the literature, a prognostic factor is a measurement that is associated with clinical outcome in the absence of therapy or with the application of a standard therapy that patients are likely to receive; a predictive factor is a measurement that is associated with response or lack of response to a particular therapy $(23,24)$. In conclusion, SWOG pretreatment risk groups may not be consistent as prognostic markers, but may be more reliable as predictive markers for response to standard therapy, while complete response achievement is a prognostic markers as it affects outcome.

\section{References}

1. Becker MW and Jordan CT: Leukemia stem cells in 2010: Current understanding and future directions. Blood Rev 25: 75-81, 2011.

2. Giles FJ, Keating A, Goldstone AH, Avivi I, Willman CL and Kantarjian HM: Acute myeloid leukemia. Hematology Am Soc Hematol Educ Program: 73-110, 2002.

3. Chen J, Odenike O and Rowley JD: Leukemogenesis: More than mutant genes. Nat Rev Cancer 10: 23-36, 2010.

4. Vardiman JW, Harris NL and Brunning RD: The World Health Organization (WHO) classification of the myeloid neoplasms. Blood 100: 2292-2302, 2002. 
5. Yates JW, Wallace HJ Jr, Ellison RR and Holland JF: Cytosine arabinoside (NSC-63878) and daunorubicin (NSC-83142) therapy in acute nonlymphocytic leukemia. Cancer Chemother Rep 57: 485-488, 1973.

6. Slovak ML, Kopecky KJ, Cassileth PA, Harrington DH, Theil KS, Mohamed A, Paietta E, Willman CL, Head DR, Rowe JM, et al: Karyotypic analysis predicts outcome of preremission and postremission therapy in adult acute myeloid leukemia: A Southwest Oncology Group/Eastern Cooperative Oncology Group study. Blood 96: 4075-4083, 2000.

7. Grimwade D, Hills RK, Moorman AV, Walker H, Chatters S, Goldstone AH, Wheatley K, Harrison CJ and Burnett AK National Cancer Research Institute Adult Leukemia Working Group: Refinement of cytogenetic classification in acute myeloid leukemia: Determination of prognostic significance of rare recurring chromosomal abnormalities among 5876 younger adult patients treated in the United Kingdom Medical Research Council trials. Blood 116: 354-365, 2010.

8. Grimwade D, Walker H, Harrison G, Oliver F, Chatters S, Harrison CJ, Wheatley K, Burnett AK and Goldstone AH; Medical Research Council Adult Leukemia Working Party: The predictive value of hierarchical cytogenetic classification in older adults with acute myeloid leukemia (AML): Analysis of 1065 patients entered into the United Kingdom Medical Research Council AML11 trial. Blood 98: 1312-1320, 2001.

9. Byrd JC, Mrózek K, Dodge RK, Carroll AJ, Edwards CG, Arthur DC, Pettenati MJ, Patil SR, Rao KW, Watson MS, et al: Pretreatment cytogenetic abnormalities are predictive of induction success, cumulative incidence of relapse and overall survival in adult patients with de novo acute myeloid leukemia: Results from Cancer and Leukemia Group B (CALGB 8461). Blood 100: 4325-4336, 2002.

10. Walter RB, Kantarjian HM, Huang X, Pierce SA, Sun Z, Gundacker HM, Ravandi F, Faderl SH, Tallman MS, Appelbaum FR and Estey EH: Effect of complete remission and responses less than complete remission on survival in acute myeloid leukemia: A combined Eastern Cooperative Oncology Group, Southwest Oncology Group and M. D. Anderson Cancer Center study. J Clin Oncol 28: 1766-1771, 2010.

11. Jabbour EJ, Estey E and Kantariian HM: Adult acute myeloid leukemia. Mayo Clin Proc 81: 247-260, 2006.

12. Grimwade D, Walker H, Oliver F, Wheatley K, Harrison C, Harrison G, Rees J,Hann I, Stevens R, Burnett A and Goldstone A: The importance of diagnostic cytogenetics on outcome in AML: Analysis of 1,612 patients entered into the MRC AML 10 trial. The Medical Research Council Adult and Children's Leukemia Working Parties. Blood 92: 2322-2333, 1998.

13. Odenike O, Thirman MJ, Artz AS, Godley LA, Larson RA and Stock W: Gene mutations, epigenetic dysregulation and personalized therapy in myeloid neoplasia: Are we there yet? Semin Oncol 38: 196-214, 2011.

14. Bennet JM, Catovsky D, Daniel MT, Flandrin G, Galton DA, Gralnick HR and Sultan C: Proposals for the classification of the acute myeloid leukemias: French-American-British Cooperative Group. Br J Hematol 33: 451-458, 1976.

15. British Committee for Standards in Hematology, Milligan DW, Grimwade D, Cullis JO, Bond L, Swirsky D, Craddock C, Kell J, Homewood J, Campbell K, et al: Guidelines on the management of acute myeloid leukemia in adults. Br J Hematol 135: 450-474, 2006.

16. Wiernik PH, Banks PL, Case DC Jr, Arlin ZA, Periman PO, Todd MB, Ritch PS, Enck RE and Weitberg AB: Cytarabine plus idarubicin or daunorubicin as induction and consolidation therapy for previously untreated adult patients with acute myeloid leukemia. Blood 79: 313-319, 1992.

17. Wiernik PH, Case DC Jr, Periman PO, Arlin ZA, Weitberg AB, Ritch PS and Todd MB: A multicenter trial of cytarabine plus idarubicin or daunorubicin as induction therapy for adult nonlymphocytic leukemia. Semin Oncol 16 (1 Suppl 2): S25-S29, 1989.

18. List AF, Spier C, Greer J, Wolff S, Hutter J, Dorr R, Salmon S, Futscher B, Baier M and Dalton W: Phase I/II trial of cyclosporine as a chemotherapy-resistance modifier in acute leukemia. J Clin Oncol 11: 1652-1660, 1993.
19. List AF, Kopecky KJ, Willman CL, Head DR, Persons DL, Slovak ML, Dorr R, Karanes C, Hynes HE, Doroshow JH, et al: Benefit of cyclosporine modulation of drug resistance in patients with poor-risk acute myeloid leukemia: A Southwest Oncology Group study. Blood 98: 3212-3220, 2001.

20. Cheson BD, Bennett JM, Kopecky KJ, Büchner T, Willman CL, Estey EH, Schiffer CA, Doehner H, Tallman MS, Lister TA, et al: Revised recommendations of the International Working Group for Diagnosis, Standardization of Response Criteria, Treatment Outcomes and Reporting Standards for Therapeutic Trials in Acute Myeloid Leukemia. J Clin Oncol 21: 4642-4649, 2003.

21. Döhner H, Estey EH, Amadori S, Appelbaum FR, Büchner T, Burnett AK, Dombret H,Fenaux P, Grimwade D, Larson RA, et al: Diagnosis and management of acute myeloid leukemia in adults: Recommendations from an international expert panel, on behalf of the European LeukemiaNet. Blood 115: 453-474, 2010.

22. Gonzalez Garcia JR and Meza-Espinoza JP: Use of the International System for Human Cytogenetic Nomenclature (ISCN). Blood 108: 3952-3953, 2006.

23. Clark GM: Prognostic factors versus predictive factors: Examples from a clinical trial of erlotinib. Mol Oncol 1: 406-412, 2008.

24. Clark GM, Zborowski DM, Culbertson JL, Whitehead M, Savoie M, Seymour L and Shepherd FA: Clinical utility of epidermal growth factor receptor expression for selecting patients with advanced non-small cell lung cancer for treatment with erlotinib. J Thorac Oncol 1: 837-846, 2006.

25. Suvajdžić N, Cvetković Z, Dorđević V, Kraguljac-Kurtović N, Stanisavljević D, Bogdanović A, Djunić I, Colović N, Vidović A, Elezović I and Tomin D: Prognostic factors for therapy-related acute myeloid leukemia (t-AML) - a single centre experience. Biomed Pharmacother 66: 285-292, 2012.

26. Farag SS, Ruppert AS, Mrózek K, Mayer RJ, Stone RM, Carroll AJ, Powell BL, Moore JO, Pettenati MJ, Koduru PR, et al: Outcome of induction and postremission therapy in younger adults with acute myeloid leukemia with normal karyotype: A Cancer and Leukemia Group B study. J Clin Oncol 23: 482-493, 2005.

27. Medeiros BC: Comparing apples and oranges in normal karyotype acute myeloid leukemia. J Clin Oncol 27: 474, 2009.

28. Christiansen DH and Pedersen-Bjergaard J: Internal tandem duplications of the FLT3 and MLL genes are mainly observed in atypical cases of therapy-related acute myeloid leukemia with a normal karyotype and are unrelated to type of previous therapy. Leukemia 15: 1848-1851, 2001.

29. Bienz M, Ludwig M, Leibundgut EO, Mueller BU, Ratschiller D, Solenthaler M, Fey MF and Pabst T: Risk assessment in patients with acute myeloid leukemia and a normal karyotype. Clin Cancer Res 11: 1416-1424, 2005.

30. Medeiros BC, Gotlib J and Zehnder J: Molecular stratification of patients with normal karyotype acute myeloid leukemia based on initial assessment of FLT3-internal tandem duplication status at first complete remission. Leuk Lymphoma 50: 851-853, 2009.

31. Medeiros BC: Role of CEBPA in normal karyotype acute myeloid leukemia. J Clin Oncol 27: 2105, 2009.

32. Yoshimoto G, Nagafuji K, Miyamoto T, Kinukawa N, Takase K, Eto T, Kato K, Hayashi S, Kamimura T, Ohno Y, et al: FLT3 mutations in normal karyotype acute myeloid leukemia in first complete remission treated with autologous peripheral blood stem cell transplantation. Bone Marrow Transplant 36: 977-983, 2005.

33. Foran JM: New prognostic markers in acute myeloid leukemia: Perspective from the clinic. Hematology Am Soc Hematol Educ Program 2010: 47-55, 2010.

34. Kadia T, Kantarjian H, Garcia-Manero G, Borthakur G, Wang X, Patel K, Jabbour E, Brandt M, Daver N, Pemmaraju N, et al: Prognostic significance of the Medical Research Council cytogenetic classification compared with the European LeukemiaNet risk classification system in acute myeloid leukemia. Br J Hematol 170: 590-593, 2015. 